\title{
Determination of Body Composition of Children from Skinfold Measurements
}

\author{
C. G. D. BROOK \\ with the technical assistance of Harriet Phillips \\ From the Department of Child Health, Institute of Child Health, London
}

\begin{abstract}
Brook, C. G. D. (1971). Archives of Disease in Childhood, 46, 182. Determination of body composition of children from skinfold measurements. Total body water was measured in 23 children aged 1 to 11 years and correlated with estimates of lean body mass derived from measurements of skinfold thickness. The correlation coefficient was $\mathbf{0 . 9 8}$. Skinfold thickness can, therefore, be used to estimate lean body mass, and thus total body fat, in young children for whom other techniques for the measurement of body composition cannot easily be used.
\end{abstract}

Several methods are available for determining the composition of the human body. These include hydrostatic weighing, absorption of gases by fat and radiography, which measure adipose tissue mass, and the estimation of total body water or potassium for the measurement of lean body mass. Many of these techniques cannot be used in children for practical or ethical reasons, and none is suitable for routine use. Several investigators (Wilmore and Behnke, 1970; Sloan and Weir, 1970) have shown that in adults measurements of skinfold thicknesses correlate with values for body fat obtained by one of the physico-chemical methods, and Durnin and Rahaman (1967) extended their studies to include 12 to 16-year-old adolescents. Because skinfold measurements are simple, safe, and painless, they are suitable for routine use in young children, and this paper describes a study correlating the results of skinfold measurements in children with measurements of total body water using deuterium oxide.

\section{Patients and Methods}

Total body water was measured by dilution of deuterium oxide in 12 boys and 11 girls aged 1 to 11 years (Table). 13 children were being investigated for obesity and 10 for short stature; none of these children had any endocrine disorder.

Deuterium oxide $(99 \cdot 8 \%$ pure made isotonic with sodium chloride) was given by intravenous injection to all children. Venous blood was collected after two hours. Deuterium oxide was extracted from whole

Received 28 August 1970. blood using a closed manifold vacuum system (Schloerb et al., 1950), and estimated by infrared spectrophotometry (Fydelor and Rawson, 1964).

Skinfold measurements were made by the same observer in the standard manner using a Harpenden skinfold caliper (Edwards et al., 1955). Measurements were made at the triceps, biceps, subscapular, and suprailiac sites in each child. Body density was calculated from the regression equations of Durnin and Rahaman (1967) for adolescents :

For boys Density $=1 \cdot 1533-0.0643 \times \log$ sum of the skinfold thicknesses at 4 sites.

For girls Density $=1 \cdot 1369-0.0598 \times \log$ sum of the skinfold thicknesses at 4 sites.

Calculation of the body fat was based on the equation given by Siri (1956):

Body fat $\%$ of weight $=\left\{\frac{4.95}{\text { Body density }}-4.5\right\} \times 100$ Lean body mass was obtained by subtracting the adipose tissue mass from the body weight.

\section{Results}

The relation between total body water determined by deuterium oxide in litres $(y)$ and the lean body mass derived from skinfold measurement in kilograms $(x)$ is shown in the figure. The regression equation is:

$$
y=0.64 x+0.89
$$

The standard deviation of the regression coefficient is $\mathbf{0 . 0 2 4}$. Though the line was not constrained to pass through zero, the intercept on the $\mathbf{x}$ axis does not differ significantly from zero. The correlation coefficient is 0.985 and the residual standard deviation is $1 \cdot 149$, which is $7.9 \%$ of the mean 


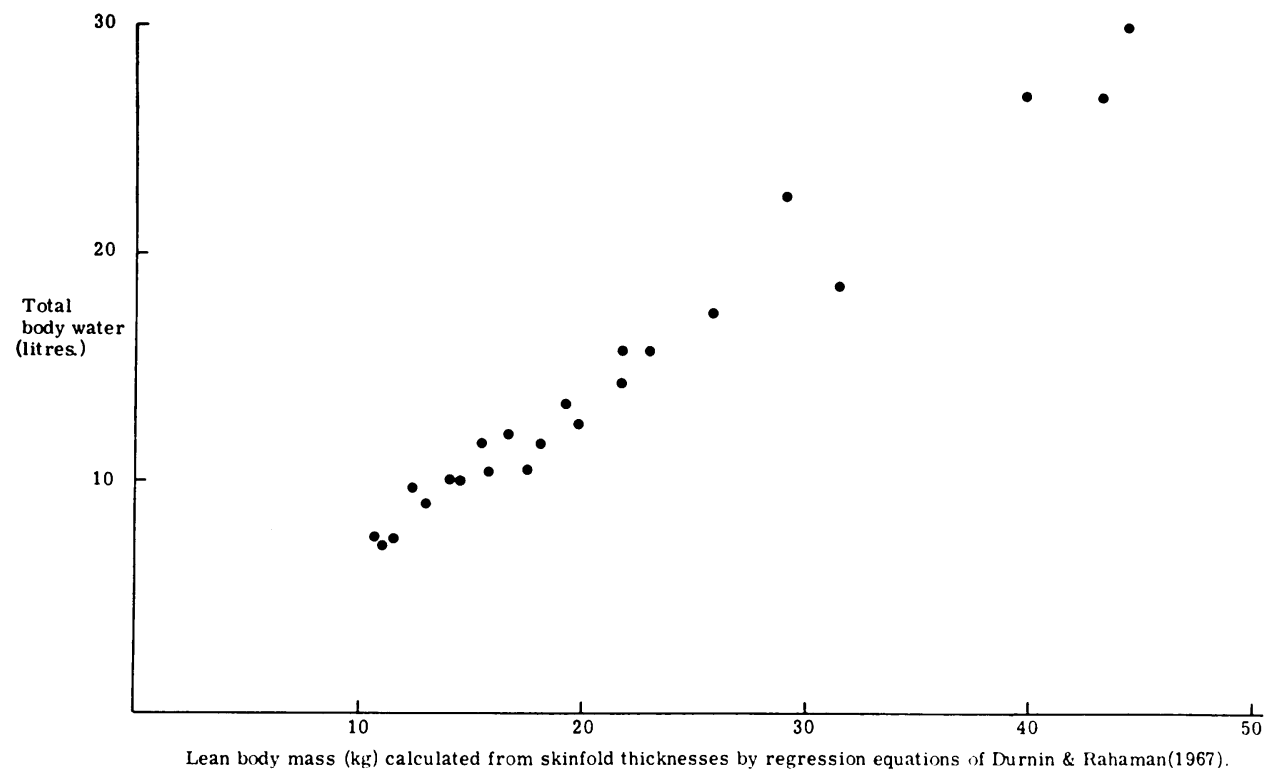

Fig.-Relation of body water and lean body mass $y=0.64 x+0.89 . \quad r=0.98$.

TABLE

Anthropometric and Body Water Measurements

\begin{tabular}{|c|c|c|c|c|c|c|c|}
\hline Age (yr) & Sex & Height $(\mathrm{cm})$ & Weight (kg) & $\begin{array}{c}\text { Total } \\
\text { Body Water } \\
(1 .)^{\star}\end{array}$ & $\begin{array}{l}\text { Sum of Skinfold } \\
\text { Thickness at } \\
4 \text { sites (mm) }\end{array}$ & $\begin{array}{l}\text { Body Fat } \\
\% \text { of } \\
\text { Weight† }\end{array}$ & $\begin{array}{l}\text { Lean Body Mass } \\
\text { Calculated from } \\
\text { Skinfold } \\
\text { Measurements } \\
(\mathbf{k g}) \ddagger\end{array}$ \\
\hline $\begin{array}{r}1 \cdot 4 \\
1 \cdot 6 \\
3 \cdot 0 \\
3 \cdot 4 \\
3 \cdot 8 \\
5 \cdot 3 \\
5 \cdot 3 \\
5 \cdot 6 \\
5 \cdot 8 \\
6 \cdot 2 \\
6 \cdot 6 \\
6 \cdot 9 \\
7 \cdot 1 \\
7 \cdot 2 \\
7 \cdot 3 \\
7 \cdot 6 \\
7 \cdot 9 \\
8 \cdot 9 \\
9 \cdot 3 \\
10 \cdot 4 \\
10 \cdot 6 \\
10 \cdot 8 \\
11 \cdot 1\end{array}$ & $\begin{array}{l}\text { M } \\
\text { M } \\
\text { F } \\
\mathbf{M} \\
\mathbf{F} \\
\mathbf{F} \\
\mathbf{M} \\
\mathbf{F} \\
\mathbf{M} \\
\mathbf{F} \\
\mathbf{F} \\
\mathbf{M} \\
\mathbf{M} \\
\mathbf{M} \\
\mathbf{F} \\
\mathbf{M} \\
\mathbf{F} \\
\mathbf{M} \\
\mathbf{M} \\
\mathbf{M} \\
\mathbf{F} \\
\mathbf{F} \\
\mathbf{F}\end{array}$ & $\begin{array}{r}82 \cdot 5 \\
93 \cdot 7 \\
88 \cdot 9 \\
86 \cdot 8 \\
105 \cdot 2 \\
126 \cdot 4 \\
90 \cdot 0 \\
102 \cdot 1 \\
124 \cdot 6 \\
124 \cdot 1 \\
123 \cdot 6 \\
95 \cdot 1 \\
110 \cdot 2 \\
98 \cdot 9 \\
125 \cdot 0 \\
101 \cdot 0 \\
126 \cdot 3 \\
119 \cdot 5 \\
110 \cdot 8 \\
146 \cdot 4 \\
151 \cdot 2 \\
143 \cdot 0 \\
130 \cdot 0\end{array}$ & $\begin{array}{l}15 \cdot 0 \\
26 \cdot 2 \\
21 \cdot 9 \\
26 \cdot 0 \\
26 \cdot 2 \\
49 \cdot 7 \\
13 \cdot 2 \\
16 \cdot 1 \\
44 \cdot 5 \\
31 \cdot 3 \\
35 \cdot 2 \\
16 \cdot 4 \\
17 \cdot 5 \\
13 \cdot 0 \\
31 \cdot 5 \\
16 \cdot 5 \\
39 \cdot 3 \\
26 \cdot 3 \\
18 \cdot 0 \\
69 \cdot 8 \\
64 \cdot 6 \\
70 \cdot 0 \\
25 \cdot 8\end{array}$ & $\begin{array}{r}7 \cdot 56 \\
11 \cdot 73 \\
10 \cdot 12 \\
10 \cdot 59 \\
12 \cdot 33 \\
18 \cdot 96 \\
7 \cdot 65 \\
9 \cdot 91 \\
22 \cdot 75 \\
14 \cdot 43 \\
15 \cdot 83 \\
9 \cdot 03 \\
10 \cdot 52 \\
7 \cdot 35 \\
15 \cdot 97 \\
10 \cdot 22 \\
17 \cdot 49 \\
12 \cdot 62 \\
11 \cdot 86 \\
30 \cdot 24 \\
27 \cdot 18 \\
27 \cdot 20 \\
13 \cdot 52\end{array}$ & $\begin{array}{r}48 \cdot 2 \\
87 \cdot 6 \\
81 \cdot 6 \\
101 \cdot 4 \\
99 \cdot 9 \\
102 \cdot 5 \\
33 \cdot 9 \\
34 \cdot 0 \\
106 \cdot 9 \\
62 \cdot 9 \\
87 \cdot 6 \\
40 \cdot 5 \\
21 \cdot 8 \\
25 \cdot 4 \\
65 \cdot 1 \\
24 \cdot 6 \\
85 \cdot 2 \\
54 \cdot 5 \\
24 \cdot 0 \\
130 \cdot 0 \\
113 \cdot 2 \\
112 \cdot 0 \\
40 \cdot 6\end{array}$ & $\begin{array}{l}23 \cdot 7 \\
31 \cdot 3 \\
34 \cdot 1 \\
33 \cdot 2 \\
36 \cdot 6 \\
36 \cdot 9 \\
19 \cdot 2 \\
23 \cdot 5 \\
33 \cdot 9 \\
30 \cdot 9 \\
34 \cdot 9 \\
21 \cdot 5 \\
13 \cdot 8 \\
15 \cdot 7 \\
31 \cdot 3 \\
15 \cdot 3 \\
34 \cdot 6 \\
25 \cdot 2 \\
15 \cdot 0 \\
36 \cdot 5 \\
38 \cdot 1 \\
38 \cdot 0 \\
25 \cdot 6\end{array}$ & $\begin{array}{l}11 \cdot 5 \\
18 \cdot 0 \\
14 \cdot 4 \\
17 \cdot 4 \\
16 \cdot 6 \\
31 \cdot 4 \\
10 \cdot 7 \\
12 \cdot 3 \\
29 \cdot 0 \\
21 \cdot 6 \\
22 \cdot 9 \\
12 \cdot 9 \\
15 \cdot 1 \\
11 \cdot 0 \\
21 \cdot 7 \\
14 \cdot 0 \\
25 \cdot 7 \\
19 \cdot 7 \\
15 \cdot 3 \\
44 \cdot 3 \\
40 \cdot 0 \\
43 \cdot 4 \\
19 \cdot 2\end{array}$ \\
\hline
\end{tabular}

*Estimated by dilution of deuterium oxide.

†Calculated from skinfolds and regression equations of Durnin and Rahaman (1967).

$\ddagger$ Multiplication of the values given for lean body mass by the coefficient $0 \cdot 73$ of Rathbun and Pace (1945) gives the theoretical body water. 
value of body water. Thus body water was predicted from skinfolds with an accuracy of $\pm 15.8 \%$ in $95 \%$ of cases.

\section{Discussion}

Total body fat can be calculated from the total water content of the body if it is assumed that the percentage of water in the lean body is constant. Rathbun and Pace (1945) measured the water content of the lean body in animals and found it to contain $73 \%$ water, i.e. the correlation between the water content and the lean body mass had a regression coefficient of $0 \cdot 73$. A similar figure has been found from direct chemical analysis of adult humans (Brožek et al., 1963). In newborn infants, however, Widdowson and Spray (1951) showed that water comprised $82 \%$ of the lean body. The amount of water has been shown to fall over the first few months of life and reaches a steady state by 4 months of age (Owen, Jensen, and Fomon, 1962). Mellits and Cheek (1968) found it possible to employ a constant factor for the water content of the body from 1 month to adolescence.

The present study shows that over a wide range of age and physique skinfolds are a relatively good predictor of body water in prepubertal children. The regression coefficient of 0.64 differs, however, from the theoretical coefficient of $0 \cdot 73$. Assuming that the water content of the lean body of children after the first few months of life does not differ from that of adults and other animals, the difference is likely to be due to the use of regression equations, which were described for adolescents (Durnin and Rahaman, 1967), in the calculations of lean body mass from skinfold thicknessess. If the data for the lean body mass in the present study are adjusted to give a regression coefficient of 0.73 against total body water, new regression equations are required for the calculation of body density (and hence lean body mass) from skinfold measurements. These equations are:
For boys Density $=1 \cdot 1690-0.0788 \times \log$ sum of skinfold thicknesses at 4 sites.

For girls Density $=1.2063-0.0999 \times \log$ sum of skinfold thicknesses at 4 sites.

It is suggested that the use of these equations is more appropriate for prepubertal children.

I would like to thank the Wellcome Trust for financial support.

\section{REFERENCES}

Brožek, J., Grande, F., Anderson, J. T., and Keys, A. (1963). Densitometric analysis of body composition. Annals of the New York Academy of Sciences, 110, 113.

Durnin, J. V. G. A., and Rahaman, M. M. (1967). The assessment of the amount of fat in the human body from measurements of skinfold thickness. British fournal of Nutrition, 21, 681.

Edwards, D. A. W., Hammond, W. H., Healy, M. J. R., Tanner, J. M., and Whitehouse, R. H. (1955). Design and accuracy of calipers for measuring subcutaneous tissue thickness. British fournal of Nutrition, 9, 133.

Fydelor, P. J., and Rawson, D. S. (1964). The measurement of deuterium in water near natural concentrations using a standard infra red spectrophotometer. United Kingdom Atomic Energy Authority AERE-R 4785.

Mellits, E. D., and Cheek, D. B. (1968). In Human Growth, p. 137. By D. B. Cheek. Lea and Febiger, Philadelphia.

Owen, G. M., Jensen, R. L., and Fomon, S. J. (1962). Sexrelated difference in total body water and exchangeable chloride during infancy. Fournal of Pediatrics, 60, 858.

Rathbun, E. N., and Pace, N. (1945). Studies on body composition. I. Determination of total body fat by means of body specific gravity. Fournal of Biological Chemistry, 158, 667.

Schloerb, P. R., Friis-Hansen, B. J., Edelman, I. S., Solomon, A. K., and Moore, F. D. (1950). The measurement of total body water in the human subject by deuterium oxide dilution. Fournal of Clinical Investigation, 29, 1296.

Siri, W. E. (1956). Body composition from fluid spaces and density. MS UCRL 3349. Donner Laboratory, University of California.

Sloan, A. W., and Weir, J. B. de V. (1970). Normograms for prediction of body density and total body fat from skinfold measurements. Fournal of Applied Physiology, 28, 221.

Widdowson, E. M., and Spray, C. M. (1951). Chemical development in utero. Archives of Disease in Childhood, 26, 205.

Wilmore, J. H., and Behnke, A. R. (1970). An anthropometric estimation of body density and lean body weight in young women. American fournal of Clinical Nutrition, 23, 267.

Correspondence to Dr. C. G. D. Brook, Institute of Child Health, 30 Guilford Street, London W.C.1. 